ORIGINAL ARTICLE

\title{
Short Term Results of Ceramic on Ceramic Total Hip Arthroplasty
}

\author{
Mohamed Adel Shafik I, Ahmed Emad El-din Radi II, El-Sayed El-Etewy Soudy I, Ehab \\ Mohamed Shehata ${ }^{{ }^{*}}$ \\ I: Orthopedic Surgery Department, Faculty of Medicine, Zagazig University, Egypt \\ II: Orthopedic Surgery Department, Faculty of Medicine, Ain-Shams University Egypt
}

* Corresponding Author: Ehab Mohamed Shehata

Assistant Lecturer Orthopedic

Surgery, Faculty of Medicine,

Zagazig University, Egypt

E mail:

ehabmohamedshehata1@gmail.com

Submit Date: 01-04-2019

Revise Date: 13-04-2019

Accept Date: 14-04-2019

\begin{abstract}
Background: Ceramic on ceramic (COC) total hip arthroplasty is now a standard procedure in the management of degenerative hip joint disorders. The new operative techniques has made the procedure an easy process to operate and with good results for young individuals. Methods: Our study was performed on 24 patients that were operated at Orthopedic department, Zagazig university and Ain-Shams university hospital in the period between August 2014 to August 2016. All cases were treated by COC THA. 11 males and 13 females with mean age of 36 years (range: 20-52). The etiology was femoral head avascular necrosis in 16 hips, and posttraumatic hip arthritis in 6 patients and ankylosing spondylitis in 2 hips. Clinically, the indications of operation were intolerable pain, limitation of hip motions and flexion adduction deformity. Clinical evaluation by Harris Hip Score preoperatively, postoperatively and at follow up visits was done. Results: The age of the patients was between 20 and 52 years with mean 36 years. Regarding sex distribution $54.2 \%$ were female (Table 1). There was statistical significant increase in Harris score grading among cases postoperative compared to preoperative. Excellent results were in 18 hips (75\%), and good results in $2(8.3 \%)$, fair in 3 hips $(12.5 \%)$, and 1 hip (4.2\%) had poor results (Table 2). There were complications in $33.3 \%$ of patients, one case had linear breakage, 3 cases had head dislocation, two infected cases, one case suffered from squeaking and one case revised. Conclusion: 21 months follow-up of total hip replacement using ceramic on ceramic couplings are fairly encouraging. Combined with suitable indications, COC implant ensures good clinical outcomes with minimal complications and low rate of loosening. The ceramic bearings are recommended for hip replacement in relatively young patients. We recommend longer term follow up for better evaluation of the longevity of the prosthesis.
\end{abstract}

Keywords: Total hip, ceramic, young adult.

\section{INTRODUCTION}

Orer eramic-on-ceramic hips release the least volumes of micro particles during friction, which subsequently reduces cytokine release, thus diminishing the hazard of implant early loosening .(1) Polyethylene wear and the resultant osteolysis is the main long-term problem affecting total hip arthroplasty survivorship. Alternative surfaces in total hip replacement have been developed in an attempt to reduce wear and improve implant durability.(2) Development of a new alumina matrix composite ceramic improves wear while diminishing the hazard of fracture with the alumina design. This composite ceramic consists of $82 \%$ alumina and $17 \%$ zirconia. Chromium oxide $(0.5 \%)$ is added to increase hardness and strontium crystals $(0.5 \%)$ is added to enhance toughness and diffuse crack energy. (3)

\section{METHODS}

This was a prospective study in concordance with STARD guidelines conducted over a period of two years from April 2014 to April 2016 in Orthopedic Department, Zagazig university hospitals .Written consent was obtained from all patients included in our study .IRB, Zagazig faculty of medicine has given approval to our study. No conflict of interest. This study 
performed upon 24 hips in 24 cases with hip disease. The study was done on the left side of 4 cases and right side of 15 cases. 5 cases had bilateral hip disease but only operated on one side because in these 5 cases the pathology was present to a less severe degree in the contralateral side in 2 cases who were operated early with core decompression. The other three cases that both hips needed to be operated, in two of them the other hip was operated by another surgeon earlier by COC THR, the third case only one limb involved in this study because the patient refused to be operated on the other limb. All cases were subjected to the following protocol:

1. Full history taking with special emphasis on: name, age, sex, address and past history of orthopedic surgery.

2. Detailed general examination for exclusion of other medical or systemic disease. Then local hip examination including site of tenderness, range of motion and leg-length discrepancy.

3. Back examination and knee examination for exclusion of other pathology.

4. All cases were subjected to pelvic X-ray.

5. Some cases were subjected to computerized tomography. (case 11, 16 and 17)

6. Case 2 was examined by MRI (1.5 tesla).

7. All cases were evaluated by Harris hip score.

\section{Surgical technique}

Spinal or epidural anesthesia was given. All operations were done through the lateral Hardinge approach modified by Radi procedure (4)in lateral position. In all cases, the ceramic on ceramic (Zimmer Biomett U.S.A Company) was used. The acetabular cup was anatomic and secured by two or three screws, while the femoral stem was press fitted. Postoperative Clexane 40 I.U was used to prevent deep venous thrombosis in all cases. Indomethacin $50 \mathrm{mg}$ daily dose for four weeks was given for prevention of heterotopic ossification. Partial weight bearing was permitted using axillary crutches in the first 45 weeks postoperative and full weight bearing with elbow crutch in the contralateral side started after 6 to 10 weeks.

\section{RESULTS}

The age of the patients was between 20 and 52 years with mean 36 years. Regarding sex distribution $54.2 \%$ were female (table 1). 50\% of the studied groups were from rural area and $50 \%$ were from urban. Regarding occupation $33.3 \%$ of the studied groups were clerks and $29.2 \%$ were housewives. $62.5 \%$ of the studied groups had lesion in right side. Regarding cause of lesion most frequent were fall from height and RTA (25\% \& $25 \%$ respectively) (Table 3 ). The most frequent operation techniques were previously used among the studied group was DHS (37.5\%). Regarding complain all the studied group had pain, $66.7 \%$ had limited mobility and $41.7 \%$ inability to bear weight. All patients had regular thorough follow up for a period ranging from 12 to 30 months with a mean period of 21 months (table 2). Clinically, the mean Harris Hip Score was increased from 36 (range, 15-73) to 57 (range, 16-98) $[\mathrm{p}<0.001]$. At the last follow up, excellent results were in 18 hips $(75 \%)$, good results in 2 hips (8.3\%), fair in 3 hips $(12.5 \%)$, and 1 hip (4.2\%) had poor results.

There was statistical significant increase in all categories of Harris hip score. Pain in most cases improved from moderate with occasional exacerbation (20 points) preoperative to no pain (44 points) postoperative. Limping improved markedly from moderate limping (5 points) to no limping (11 points) post-operatively. According to walking with or without support patients improved well as they used to use crutches preoperative (2 or 4 points) but postoperatively they leave crutches at all (11 points) or used cane only for long walks (7 points).

Preoperatively, patients walk only for short distances with an average for 15-30 minutes (5 points) and postoperatively they walk freely for unlimited distances (11 points). Climbing stairs was so difficult preoperative (1 point) and post-operatively improved either climbing normally or assisted with handrail (4 or 2 points). Most individuals preoperative couldn't wear shoes with ease ( 2 points) but they improved after surgery and they could wear shoes easily (4 points). Also the patient was unable to sit for $1 / 2$ an hour or less on any chair ( 0 point) and became better post-operatively and sit on any chair for one hour or more (5 points). Preoperatively, 
patients were unable to use public they became able to enter public transportation ( 0 point) but post-operatively transportation (1 point).

Table 1. Age and sex distribution among studied group.

\begin{tabular}{|c|c|c|}
\hline 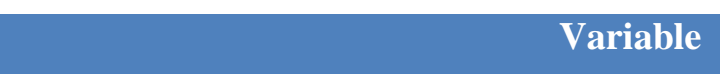 & \multicolumn{2}{|c|}{$(\mathrm{n}=24)$} \\
\hline $\begin{array}{l}\text { Age : (year) } \\
\text { Mean } \pm \text { SD } \\
\text { Range }\end{array}$ & \multicolumn{2}{|c|}{$\begin{array}{c}33.21 \pm 11.31 \\
18-63\end{array}$} \\
\hline Variable & $\mathbf{N}$ & $\%$ \\
\hline $\begin{array}{l}\text { Sex: } \\
\text { Male } \\
\text { Female }\end{array}$ & $\begin{array}{l}11 \\
13\end{array}$ & $\begin{array}{l}45.8 \\
54.2\end{array}$ \\
\hline
\end{tabular}

Table 2. Comparison of some Harris score pre and post-operative among the studied group:

\begin{tabular}{|c|c|c|c|c|c|}
\hline Variable & $\begin{array}{c}\text { Pre } \\
(n=24)\end{array}$ & $\begin{array}{l}\text { Post } \\
(n=24)\end{array}$ & $\begin{array}{l}\text { Paired } \\
\text { W }\end{array}$ & $\mathbf{P}$ & $\begin{array}{l}\% \text { of change } \\
(n=24)\end{array}$ \\
\hline $\begin{array}{l}\text { Pain: } \\
\text { Mean } \pm \text { SD } \\
\text { Median } \\
\text { Range }\end{array}$ & $\begin{array}{c}15 \pm 9.78 \\
20 \\
0-30\end{array}$ & $\begin{array}{c}40.75 \pm 7.69 \\
44 \\
10-44\end{array}$ & 4.34 & $<0.001 * *$ & $162.11 \%$ \\
\hline $\begin{array}{l}\text { Limb: } \\
\text { Mean } \pm \text { SD } \\
\text { Median } \\
\text { Range }\end{array}$ & $\begin{array}{c}4.33 \pm 2.48 \\
5 \\
0-8\end{array}$ & $\begin{array}{c}10.17 \pm 2.39 \\
11 \\
0-11\end{array}$ & 4.38 & $<0.001 * *$ & $106.97 \%$ \\
\hline $\begin{array}{l}\text { Support: } \\
\text { Mean } \pm \text { SD } \\
\text { Median } \\
\text { Range }\end{array}$ & $\begin{array}{c}2.79 \pm 2.54 \\
3 \\
0-7\end{array}$ & $\begin{array}{c}9.46 \pm 2.98 \\
11 \\
0-11\end{array}$ & 4.22 & $<0.001 * *$ & $175.87 \%$ \\
\hline $\begin{array}{l}\text { Distance walk: } \\
\text { Mean } \pm \text { SD } \\
\text { Median } \\
\text { Range }\end{array}$ & $\begin{array}{c}5.25 \pm 3.71 \\
5 \\
0-11\end{array}$ & $\begin{array}{c}10.42 \pm 2.30 \\
11 \\
0-11\end{array}$ & 3.97 & $<0.001 * *$ & $174.29 \%$ \\
\hline $\begin{array}{l}\text { Stairs: } \\
\text { Mean } \pm \text { SD } \\
\text { Median } \\
\text { Range }\end{array}$ & $\begin{array}{c}1.04 \pm 0.95 \\
1 \\
0-2\end{array}$ & $\begin{array}{c}3.33 \pm 1.24 \\
4 \\
0-4\end{array}$ & 4.32 & $<0.001 * *$ & $142.86 \%$ \\
\hline
\end{tabular}


Table 3. Side and cause distribution among studied group.

\begin{tabular}{|c|c|c|}
\hline \multirow[t]{2}{*}{ Variable } & \multicolumn{2}{|c|}{$(n=24)$} \\
\hline & No & $\%$ \\
\hline Side: & & \\
\hline Left & 4 & 16.7 \\
\hline Right & 15 & 62.5 \\
\hline Bilateral & 5 & 20.8 \\
\hline Cause: & & \\
\hline Corticosteroid induced AVN & 4 & 16.7 \\
\hline Fall from height & 6 & 25 \\
\hline Idiopathic AVN & 5 & 20.8 \\
\hline RTA & 6 & 25 \\
\hline Direct Trauma & 3 & 12.5 \\
\hline
\end{tabular}

(A)

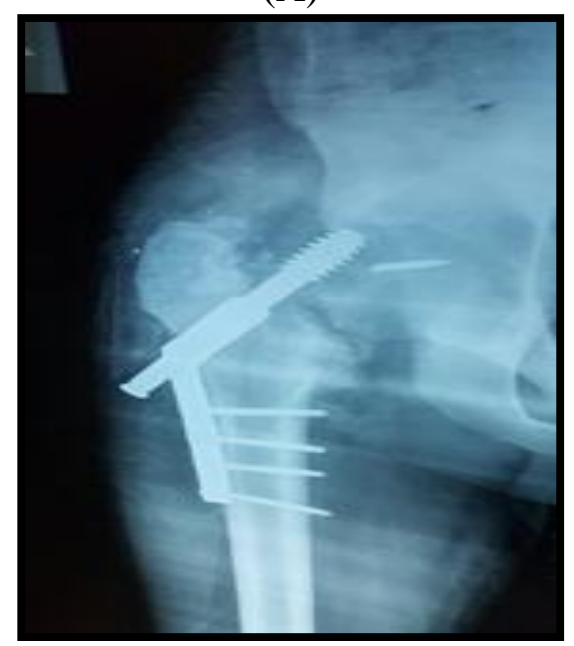

(C)

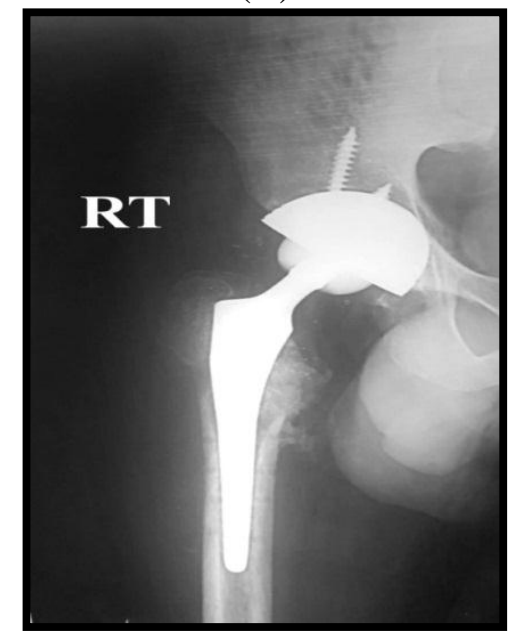

(B)

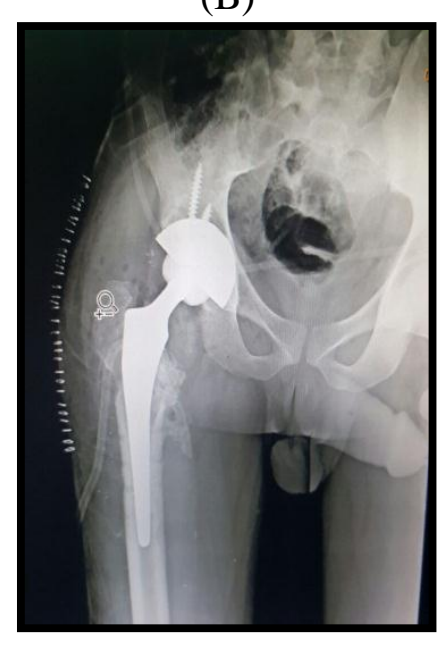

Figure 5. CASE (1), showing: A) X-ray hip joint showing un-united fracture B) Immediate follow up $x$ ray $C$ ). Follow up $x$ ray after 3 months

\section{DISCUSSION}

Ceramic on ceramic total hip replacement is one of the most effective surgical procedure for hip joint diseases. The operation provides excellent relief of pain and functional improvement for patients complaining from osteoarthritis of the hip joint. Unfortunately, young individuals with active lifestyle carry the hazard of early loosening and repeated revisions. To 
overcome these problems; more durable bearing materials have been developed.(5) Most ceramic total hip arthroplasty are performed in relatively young patient, old patients can also be treated by ceramic hip replacement but relatively less common. In this study, COC THR was performed in patients with the average age of 33 years old because of avascular necrosis (AVN) idiopathic, posttraumatic and corticosteroid induced. This finding was similar to studies conducted by Synder, et al . Synder, et al stated that $70 \%$ THR surgery was performed in under 50 year old patients. It was associated with the high survival rates without revision of $90.8-97.4 \%$ at 10 years. (6) In Cipto Mangunkusumo Hospital, there were more females who had THR in the research of Synder, et al (101 female cases and 87 male cases). In this study also females were more than males (13 female and 11 male ). (6) Most ceramic total hip patients are done for osteoarthrosis and some cases of rheumatoid arthritis. Some reports suggest that the prognosis is better when total hip arthroplasty is performed in patients with osteoarthrosis, whereas others suggest more favorable prognosis with rheumatoid arthritis. Generally, patients with osteoarthrosis have better bone quality. Rheumatoid patients tend to be less active. Review of all available reports suggests no significant changes in durability of hip replacements for these two conditions, perhaps because the differences in bone quality and activity level balance each other. (7)

In this study, patients mostly had AVN of hip posttraumatic as the underlying cause, while So, et al reported secondary osteoarthritis due to developmental hip dysplasia as the most common underlying cause, while osteoarthritis and rheumatoid arthritis of the hip were found as the second most underlying cause at his research ${ }^{(7)}$. Synder, et al also found that the most underlying cause was hip dysplasia in childhood. We got different results from them. ${ }^{(6)}$

The revision rates in the previous studies using ceramic on ceramic bearing surfaces in young patients are promising.
Patrick et al performed their study $2012^{(\mathbf{8})}$ of 24 cases young than 20 years had total hip replacement using ceramic on ceramic bearing with follow up 52 months. They had a revision rate of $8 \%$ of cases. In Young-Hoo Kim et al study $2010^{\text {(9) }}$ about cement less total hip replacement with ceramic-on ceramic bearing in patients less than 45 years, they reported $0 \%$ revision of the femoral and the acetabular components at follow up of 11.1 years in aseptic loosening and $1 \%$ revision rate in one case due to recurrent dislocation and acetabular component revision was done. In this study, revision rates and instability following ceramicon-ceramic THA at an average follow-up of 2 years, $96 \%$ of cases were functioning well. Only one case revised after ceramic liner fracture.

Squeaking was reported by one patient (4.2\%). McDonnell, et al ${ }^{(10)}$ found that 13\% of patients had audible squeaking after THR. Squeaking had multifactorial causes without any conclusion. Taylor, et al ${ }^{(11)}$ showed that squeaking occurred when head subluxates from the edge. Walter, et al ${ }^{(\mathbf{1 2})}$ suggested that squeaking may be the resonance of any metal component during edge loading. The incidence of squeaking was not associated with the acetabular cup anteversion and lateral inclination neither with the femoral head anteversion. Similar results were also reported by Restrepo, et al (13) and Hannouche, et al ${ }^{(\mathbf{1 4})}$ that the implant position was the same between the squeaking and the non-squeaking. Despite the surprising high incidence of squeaking, all patients remained satisfied with their new hip replacement.

\section{CONCLUSION}

Twenty one months (mean) follow-up of total hip replacement using ceramic on ceramic couplings are fairly encouraging. The HHS increased significantly. Combined with suitable indications, COC implant ensures good clinical outcomes with minimal complications and low rate of loosening in 12 up to 30 months follow up according to this study. The ceramic bearings are recommended for hip replacement in relatively young patients. We recommend longer term follow up for better evaluation of the longevity of the prosthesis. 
Conflict of Interest: Nothing to declare.

Financial Disclosures: Nothing to declare.

\section{REFERENCES}

1) Barrack RL, Burak $C$ and Skinner HB. Concerns about ceramics in THA. Clin Orthop Relat Res. 2004; 429:73-79.

2) William G. Hamilton MD, James P. McAuley MD, Douglas A. Dennis MD, Jeffrey A. Murphy MS, Thomas J. Blumenfeld MD and Joel Politi MD. THA With Delta Ceramic on Ceramic. Clin. Orthop. Relat. Res. 2010; 468:358-366.

3) Anwar I, Bhatnagar G and Atrah S. Delayed catastrophic failure of ceramic head in hybrid total hip arthroplasty. J Arthroplasty. 2009; 24: 158.e58.

4) Rady A.Emad, El Sayed M.N., Abdel Aal E.H.M. A modified lateral approach to the hip (European Hip Society) Demostic meeting. 2004; $14(2)$.

5) Shetty V, Shitole B, Shetty G, Thakur H and Bhandari M. Optimal bearing surfaces for total hip replacement in the young patient: a meta-analysis. Int Orthop. 2011; 35:1281.

6) Synder M, Drobniewski $M$ and Sibiński $M$. Long-term results of cementless hip arthroplasty with ceramic-on-ceramic articulation. Int Orthop. 2012; 36 (11): 2225-2229.

7) So K, Kanatani TK, Kuroda Y, Nakamura T, Matsuda $S$ and Akiyama H. Good short-term outcome of primary total hip arthroplasty with cementless bioactive glass ceramic bottom-coated implants: 109 hips followed for 3-9 years. Acta Orthop. 2012; 83 (6):599-603.

8) Patrick R, Finkbone, Eric P Severson, Miguel E Cabanela and Robert T. Trousdale. Ceramic-OnCeramic Total Hip Arthroplasty in Patients Younger Than 20 Years. The Journal of Arthroplasty. 2012; 27(2).

9) Young-Hoo Kim, Yoowang Choi and Jun-Shik Kim. Cement less total hip arthroplasty with ceramic-on-ceramic bearing in patients younger than 45 years with femoral-head osteonecrosis. Int Orthop. 2010; 34 (8):1123-112.

10)McDonnell SM, Boyce G, Baré J, Young D and Shimmin AJ. The incidence of noise generation arising from the large-diameter Delta Motion ceramic total hip bearing. Bone Joint J. 2013; 95-B (2):160-5.

11) Taylor S, Manley MT and Sutton K. The role of stripe wear in causing acoustic emissions from alumina ceramic-on-ceramic bearings. J Arthroplasty. 2007; 22 (7Suppl3):47-51.

12) Walter WL, Insley GM, Walter WK and Tuke MA. Edge loading in third generation alumina ceramic-on-ceramic bearings: stripe wear. J Arthroplasty. 2004; 19 (4): 402-413.

13) Restrepo C, Matar WY, Parvizi J, Rothman RH and Hozack WJ. Natural history of squeaking after total hip arthroplasty. Clin Orthop Relat Res. 2010; 468 (9):2340-2345.

14)Hannouche D, Zaoui A, Zadegan F, Sedel L and Nizard R. Thirty years of experience with aluminaon-alumina bearing in total hip arthroplasty. Int Orthop. 2011; 35(2):207-213.

shehata, E., radi, A., shafik, M., soudy, E. (2019). Short Term Results of Ceramic on Ceramic Total Hip Arthroplasty. Zagazig University Medical Journal, Jully. 2020 Volume 26 Issue 4 (542-547), -. doi: 10.21608/zumj.2019.11167.1176 